
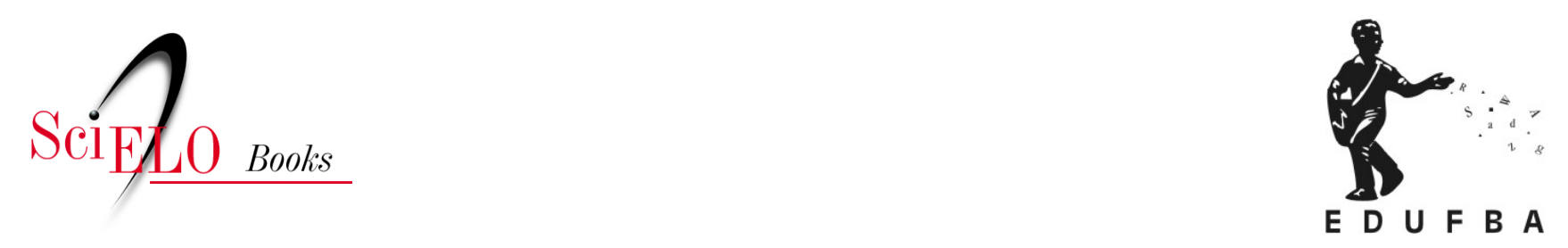

\title{
O Programa Bolsa Família a partir das crianças beneficiadas: \\ uma abordagem das moralidades engendradas pela condicionalidade escolar
}

\author{
Flávia F. Pires
}

\section{SciELO Books / SciELO Livros / SciELO Libros}

PIRES, F.F. O Programa Bolsa Família a partir das crianças beneficiadas: uma abordagem das moralidades engendradas pela condicionalidade escolar. In: MESSEDER, S., CASTRO, M.G., and MOUTINHO, L., orgs. Enlaçando sexualidades: uma tessitura interdisciplinar no reino das sexualidades e das relações de gênero [online]. Salvador: EDUFBA, 2016, pp. 91-108. ISBN: 978-85232-1866-9. https://doi.org/10.7476/9788523218669.0006.

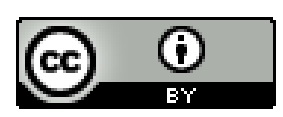

All the contents of this work, except where otherwise noted, is licensed under a Creative Commons Attribution $\underline{4.0 \text { International license. }}$

Todo o conteúdo deste trabalho, exceto quando houver ressalva, é publicado sob a licença $\underline{\text { Creative Commons }}$ Atribição 4.0. 


\title{
O Programa Bolsa Família a partir das crianças beneficiadas:
}

\author{
uma abordagem das moralidades \\ engendradas pela \\ condicionalidade escolar ${ }^{\mathrm{I}}$
}

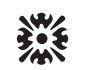

Flávia F. Pires

\section{Introdução}

Se a antropologia pauta-se desde Malinowski em captar o ponto de vista nativo, ${ }^{2}$ a ideia aqui é entender o Programa

${ }^{1}$ Agradecimentos devem ser prestados aos Catingueirenses, crianças e adultos, que generosamente participaram da pesquisa; à equipe de pesquisa que enfrentou os desafios do campo com valentia e, ao CNPq/MDS, por tornar possível esse revigorante exercício de pesquisa.

2 Embora a ideia de captar o ponto de vista nativo seja controversa para Favret-Saada (2005), Geertz (2002) afirma sua validade. 
Bolsa Família (PBF), seus efeitos na vida dos cidadãos, a partir do ponto de vista das crianças, esses sujeitos que constantemente são silenciados nas pesquisas, a despeito da sua crescente importância na vida social das famílias na contemporaneidade, como salienta Manuel Sarmento (2008). Fazemos com as crianças o que Suarez et al (2006) e Rego (2008) fazem com as mulheres: "a partir de[las]" - para usar uma expressão do professor Otávio Velho (NOGUEIRA; PIRES 20Io; PIRES; NOGUEIRA 20II) -, tentamos compreender o funcionamento e os efeitos do PBF. Isso quer dizer que "as vozes das crianças não devem ficar confinadas aos assuntos infantis", como afirma Allison James (2007, p. 267). Nesse sentido, situamo-nos entre os estudos que recentemente no Brasil vem tomando as crianças como sujeitos e interlocutores da pesquisa sem, no entanto, excluir os adultos, a partir de uma inspiração nos trabalhos de Christina Toren (1999).

O PBF é um programa de transferência mensal de renda condicionada que surgiu em 2003 e foi sancionado em 2004, a partir da unificação de uma série de programas sociais. O PBF é responsável, junto com outros programas de transferência de renda, por 21\% na queda na desigualdade no Brasil (1995-2004). Junto com o Benefício de Prestação Continuada foi responsável por $28 \%$ da redução do Índice Gini ${ }^{4}$ no mesmo período. O custo do Programa é de cerca de $0,4 \%$ do Produto Interno Bruto (PIB) nacional (R \$I,4 bilhão em março 20II), ou seja, considerado baixo, tendo em vista seus impactos macroeconômicos e sociais (SOARES et al., 2006). Como afirmam Medeiros et al (2007, p. 2I): "O lado positivo dos programas analisados é indiscutível. Seus impactos sobre pobreza e desigualdade são visíveis”. (PIRES 20I3, 20I4; MEDEIROS et al 2007; LAVINAS; BARBOSA, 2000).

Embora houvesse por parte da academia, no início de sua implantação, uma reação à exigência de condicionalidades que parecem ferir os direitos

\footnotetext{
3 "the voices of children should not be confined to childish concerns".

${ }^{4}$ O Índice ou Coeficiente Gini serve para medir a desigualdade social.
} 
humanos (ZIMMERMAM, 2006; SILVA 2007; DINIZ 2007); frente aos resultados positivos parece-nos que hoje o debate em torno do PBF volta-se para o seu aperfeiçoamento e as estratégias para lidar com o objetivo último do Programa: a quebra do círculo intergeracional da pobreza e criação de uma cultura cidadã, que parecem ainda estar distante de serem alcançadas. Por isso, vemos crescer os estudos sobre: avaliação; o empoderamento feminino e a consequente reestruturação do poder e status dos membros familiares (REGO, 2008; SUÁREZ et al., 2006; PIRES, 20I4); a escola e os entraves para uma escolarização de qualidade (MONNERAT et al. 2007); a precária rede de assistência à saúde (SILVA, 2007); o trabalho infantil (PIRES; JARDIM, 20I4), dentre outros.

\section{Objetivos}

Este artigo tem como objetivo apresentar alguns resultados de pesquisas de campo realizadas entre 2009 a 201 n na Universidade Federal da Paraíba (UFPB), sob coordenação da professora Flávia Ferreira Pires, com a equipe de pesquisadores composta por Patrícia Oliveira Santana dos Santos, Fernando Antonio Dornelas Belmont Neri, Edilma Nascimento Sousa, Christina Glayds Nogueira Mingarelli, Daniela Oliveira Silveira, Christiane Rocha Falcão, Jéssica Karoline Rodrigues, Tatiana Benjamin, Antônio da Silva e George Ardilles da Silva Jardim. Aqui nos deteremos a realizar uma avaliação do $\mathrm{PBF}$, levando em conta a opinião e a voz das crianças catingueirenses beneficiadas.

As pesquisas têm proporcionado vários debates que não poderão ser aqui analisados. Patrícia Oliveira Santos (20I4) no Programa de Pós-Graduação em Antropologia (UFPB), no curso do mestrado, dedicou-se a compreender as consequências das condicionalidades, cuja punição apenas incide sobre as famílias com crianças em idade escolar, tema o qual também foi debatido na sua monografia de fim de curso (Santos, 20II). Jéssica Silva (20II) dedicou sua monografia de fim de curso a entender a profundidade das mudanças sociais como resultado da expansão do 
consumo, principalmente infantil, propiciado pelo benefício. Edilma do Nascimento Souza (20II) e George Ardilles Silva Jardim (20IOa) nas suas monografias de fim de curso dedicaram-se à dinâmica familiar geracional no que diz respeito a escolarização das crianças mais jovens, em detrimento das gerações anteriores. George continua pensando como o PBF atravessa o tema do trabalho infantil através de um recorte geracional. Com ele escrevemos um artigo que sugere a ideia de uma "geração Bolsa Família”. (PIRES; JARDIM, 20I4) Além desses, Antonio Silva (20II), Silva e Pires (20II), Benjamin 20I0, Pires e colaboradores (20II), Silva Jardim (2OIOb) são apenas alguns estudos realizados pelo nosso grupo de pesquisa Criança: Sociedade e Cultura (CRIAS) e dialogam intensamente com a pesquisa aqui apresentada.

Nesse sentido, o texto aqui apresentado tem como objetivo central realizar uma avaliação do PBF na cidade de Catingueira, Paraíba, a partir das crianças. Para isso, lançaremos mão de alguns dados empíricos considerados relevantes pelos próprios nativos quando o assunto é o Programa. Dedicaremos atenção ao papel da condicionalidade escolar na manutenção do benefício e discutiremos as consequências da imposição da frequência escolar para a população estudada de um ponto de vista moral.

\section{Metodologia}

Usamos como técnica de pesquisa a observação participante, na medida em que cada pesquisador ficou "hospedado" na casa de uma família beneficiada, ali realizando suas refeições, as pernoites e vivenciando o cotidiano familiar. Além disso, a equipe realizou "Oficinas de Pesquisa" que funcionaram por dois dias, em dois turnos e aconteceram em uma das escolas da cidade, em duas salas de aula adequadamente preparadas, durante as férias escolares. As Oficinas de Pesquisa consistiram em seis grupos focais de aproximadamente i hora e 30 minutos, com crianças de 6 a 8 anos (dois grupos), 9 a Io anos (dois grupos), e II a I2 anos (dois grupos), e desenhos e redações temáticas. Foi solicitado às crianças que desenhassem ou escrevessem sobre o PBF e uma vez terminada a atividade, 
as crianças apresentaram suas obras para os colegas e os pesquisadores. (PIRES, 200Ira, p. 31-62) As atividades nas “Oficinas de Pesquisa” eram estruturadas da seguinte forma: boas vindas; solicitação do consentimento das crianças em participar da pesquisa, pedido de autorização para uso dos desenhos, redações e depoimentos; apresentação de cada participante através de uma brincadeira; rodada de perguntas (grupo focal propriamente dito); pausa para lanche; produção de desenhos e redações; socialização dos desenhos e redações; e finalmente a despedida com uma brincadeira. As perguntas versavam sobre o entendimento e avaliação do $\mathrm{PBF}$, acesso ou não a bens de consumo e serviços infantis e familiares, empoderamento feminino e infantil, percepções de classe social, trabalho e escola.

Vários acontecimentos sensibilizariam a equipe, como quando Júlio César, de 7 anos de idade, que ao invés de devorar o seu sanduíche, como as outras crianças faziam, preferiu guardá-lo para levar para sua avó. As precárias condições de vida das famílias "hospedeiras", que em alguns casos não dispunham de água encanada e saneamento básico, levando a pesquisadora a apreciar a água que sai da torneira na pia da sua cozinha não mais como regra, mas como uma excepcionalidade. $\mathrm{O}$ envolvimento afetivo criado entre pesquisadores e as crianças das casas onde moraram, especialmente em uma casa chefiada pelo pai, cuja mãe estava ausente. As negociações entre pesquisadores e nativos foram constantes e objeto de intensas discussões no grupo de pesquisa; e poderiam ser objeto de um artigo, tamanha a fecundidade desses debates, no entanto, apresento apenas dois rápidos episódios. Alguns catingueirenses ficaram receosos com a nossa presença, associando-nos aos "fiscais de governo" que vinham destituí-los de seu direito ao benefício. Esse medo nos fala da precariedade histórica da garantia dos direitos sociais, que são entendidos como se pudessem, ao sabor de qualquer evento, serem revogados. Outro evento diz respeito a ajuda de custo que os pesquisadores deram às famílias, como forma de recompensá -los pela gentileza em nos receber. No entanto, o dinheiro foi rapidamente isento de seu teor mercantilista na medida em que foi usado para comprar 
"gentilezas" para o próprio pesquisador, como bolo, refrigerante, presentes, etc., num estonteante exemplo do segundo movimento exigido pela dádiva, segundo Marcel Mauss (1974) .

Catingueira, o município escolhido para a realização da pesquisa, é uma cidade pequena, com 4.812 habitantes segundo o Censo 20I0, Índice de Desenvolvimento Humano Municipal (IDHM) de 0,56 segundo Programa das Nações Unidas para o Desenvolvimento (PNUD) 2000, localizada no semiárido do Estado da Paraíba, no Alto-Sertão; cuja população, com raízes camponesas, divide-se entre a zona urbana e a zona rural, chamada de "sítios". Um contingente populacional estimado de 2.992 pessoas, ou seja, $62 \%$ da população5 é beneficiário do Programa (foram beneficiadas 8I3 famílias no mês de setembro de 20II), junte-se a isso a baixa monetização da região, e temos a constatação de que os efeitos do $\mathrm{PBF}$ podem ser ali mais facilmente observados, em comparação às cidades de médio e grande porte, aspecto também ressaltado pelo Relatório Executivo do Centro de Desenvolvimento e Planejamento Regional da Universidade Federal de Minas Gerais (CEDEPLAR) (2007). Do total de I.I9o famílias cadastradas, I.I5I contam com renda per capita mensal de até I/2 salário mínimo, o que as caracteriza como extremamente pobres. Do ponto de vista da economia local, as famílias sobrevivem através da agricultura de subsistência, pequenos comércios, empregos na prefeitura e benefícios, como o PBF e as aposentadorias.

\section{Resultados e discussão}

Concentramos nosso foco na questão da escola, na medida em que a continuidade dos estudos é o que garante o recebimento do benefício, para a população pesquisada.

Embora o dinheiro seja endereçado pelo governo às mães, foi observado que elas priorizam as crianças no momento das compras, mas também

5 Calculado a partir da Média de Pessoas por Domicílio (Censo IBGE, 2010) (3,68), do número de habitantes e de famílias beneficiadas. 
transferem diretamente parte do dinheiro às crianças. Não é incomum que a criança tenha a senha de acesso ao recurso e esteja habilitada pela mãe a retirá-lo. Quanto aos valores, as mães geralmente repassam de $\mathrm{R} \$ 0,25$ a $\mathrm{R} \$ 2,00 / \mathrm{R} \$ 5,00$ para as crianças pequenas e até $\mathrm{R} \$ 15,00 / \mathrm{R}$ \$20,00 para os adolescentes. Isto funciona como incentivo à escolarização e é uma forma de fazer justiça para com aquela criança que vem se esforçando nos estudos. Vale destacar, como faz Rego (2008), que a constância do recebimento, o que possibilita o planejamento familiar, é um aspecto muito ressaltado pelas famílias beneficiadas e, segundo Hanlon et al (20IO), essencial para que as transferências de renda sejam de fato políticas de desenvolvimento e não apenas assistencialistas.

Se o benefício é da família, por que as crianças são priorizadas? É uma pergunta importante a ser respondida. Em que pese a crescente importância das crianças na vida familiar, como já destacado, a população local parece lançar mão da historicidade das políticas sociais a fim de dotar ao benefício seu destino. Embora os gastos com o benefício do PBF não sejam tutelados pelo governo - o que representa, segundo Lavinas \& Barbosa (2000), um avanço em relação aos outros programas sociais no Brasil, como o Vale-Gás, o Fome-Zero etc. -, o PBF parece ter sido assimilado a partir da prioridade às crianças, parcialmente explicado pela sua semelhança com e procedência do Programa Bolsa Escola (PBE). Parece-nos então que, do ponto de vista nativo, o PBF é entendido como uma continuidade do seu antecessor, o PBE, e nesse sentido, é importante lembrar que o PBE constituía-se em um recurso destinado exclusivamente às crianças. Além disso, o PBF utiliza-se da condicionalidade escolar como forma de garantia do benefício, o que acaba por enfatizar o papel das crianças e dos adolescentes no recebimento do dinheiro.

O PBF traz como prerrogativa fundamental a escola, como primeiro compromisso das crianças. Em consonância com os ideais modernos (ARIÈS, I98I), para o PBF lugar de criança é na escola. Isso se dá através da condicionalidade escolar, que obriga as crianças de 6 a 15 anos de idade a uma frequência escolar mínima de $85 \%$ da carga horária e aos adolescentes 
de I6 e I7 anos de idade a uma frequência escolar mínima de 75\% da carga horária.

Embora a escola já estivesse presente no município para a geração das mães, a valorização dos estudos por parte da família, principalmente das meninas, não era largamente observada. Somava-se, para a geração das avós, todavia, a escassez de escolas no município o que representava um duplo impedimento à escolarização: escassez de escolas e falta de valorização dos estudos por parte da família. Para as crianças dos sítios, principalmente os grandes deslocamentos necessários para se chegar à escola mais próxima eram suficientes para inviabilizar o estudo formal. A falta de incentivo das famílias foi mais observada no caso das mulheres, que ouviam de seus pais que mulher não precisava aprender a ler e escrever, alardeando os perigos morais da atividade. Embora mesmo no caso dos homens, poucas foram as famílias entrevistadas em que os pais incentivavam a escolarização. (PIRES; JARDIM, 20I4)

Hoje o acesso à escolarização é entendido como completamente diferente dos tempos das avós/avôs e das mães/pais, ressaltando-se a facilidade de acesso à escola e à escolarização e os avanços alcançados. Uma mãe (40 anos) de dois adolescentes, quando entrevistada, nos afirmou que sempre aconselha seus filhos a estudarem, dizendo-lhes:

\section{[...] estudem! Porque boje é muito fácil, o governo até paga para vocês estudarem.}

Do ponto de vista do Ministério do Desenvolvimento Social e Combate à Fome MDS, espera-se que a obrigatoriedade da frequência escolar como forma de garantir o recebimento do benefício seja capaz de motivar as famílias a mandarem suas crianças para a escola, mesmo no caso daquelas famílias que não valorizam os estudos, evitando que as crianças sejam assimiladas precocemente e precariamente ao mercado de trabalho. Com olhos no futuro, espera-se que uma vez na escola, às crianças seja garantida uma melhor empregabilidade quando na idade adulta; assim 
replicando a ideia de que lugar de criança é na escola para as próximas gerações e rompendo, por fim, o círculo vicioso da pobreza que vem afetando várias gerações de famílias pobres, que pode ser pensada a partir da formulação:

Figura I - Ciclo Intergeracional da Pobreza

\section{baixa escolarização}

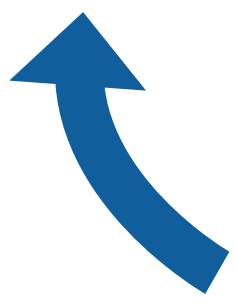

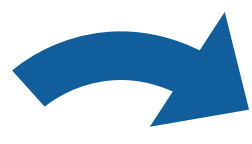

\author{
empregabilidade \\ precária ou \\ inexiste
}

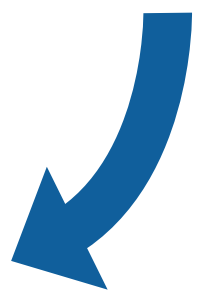

pobreza

Fonte: Elaboração do autor.

As famílias priorizam o consumo infantil e realizam o repasse financeiro direto para a criança na medida em que entendem que a condicionalidade escolar é a que, de fato, conta para o recebimento do benefício, enquanto as condicionalidades ligadas à saúde são mais entendidas como direito, na medida em que não resultam em punição (suspensões ou cortes). $\mathrm{O}$ controle da frequência escolar é bastante rígido e, de fato, leva à suspensão e ao corte do benefício, ao passo que no município ninguém tem conhecimento de benefícios suspensos em função do não cumprimento das condicionalidades da saúde. Entretanto, crianças e adultos conhecem 
pessoas que tiveram seu benefício suspenso ou cortado em função do não comparecimento ao colégio ou por erro no envio dos dados municipais escolares. (PIRES, 20I4)

$\mathrm{Na}$ cidade pesquisada, a relação do PBF com a escola é tão evidente que uma criança (Demerson, Io anos) chegou a dizer que o dinheiro do PBF passava pela professora: o governo tira o dinbeiro do banco, o banco manda para professora. Uma menina de io anos de idade, Fabíola, quando solicitada que desenhasse sobre o PBF desenhou de fato $A$ escola do bolsa familia, como podemos apreciar:

Figuras 2 - Escola do Bolsa Familia, de Fabiola, io anos

\section{Ea Errcala da borra familia}

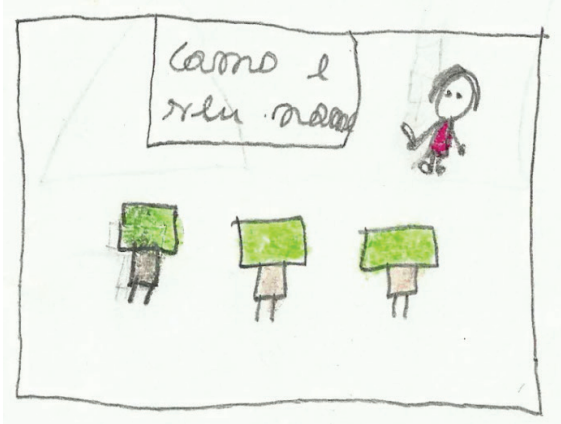

Uma vez que associam o benefício à escola, quando perguntadas de quem é o benefício, as crianças não hesitam em requerê-lo. Nildo e Paloma, ambos com II anos de idade, concordam quando foram perguntados De queméo beneficio?:

Nildo: Eu digo que é a criança que recebe.

Pesquisadora Patrícia: Por quê?

Nildo: Porque ela estuda. 
Paloma: Se é ela que estuda aí tem que receber.

Nildo: É porque ela tem que receber se é ela que está estudando.

Para isso, as crianças lançam mão da linguagem dos direitos, porque entendem que é o estudo que garante o benefício. Em foco, Lucas (II anos) e Silvana (I2 anos):

Lucas: É importante o Bolsa Família.

Pesquisadora Patrícia: Porque tu acha que é importante?

Lucas: Porque eles devem dá, por que nós estudamos.

Silvana: Nós estudamos e temos o direito de receber.

Pesquisadora Flávia: Então, toda criança que estuda tem o direito de receber?

Silvana: Tem.

Um dos problemas dos Programas de Transferência Condicionada de Renda (PTCR), como o PBF, é a necessidade de comprovação da pobreza familiar, o que segundo Suplicy (2007), leva a estigmatização do pobre. A ideia de uma renda básica da cidadania, como ocorre no Alaska, Estados Unidos, em que todos os cidadãos, independente da renda comprovada, recebem uma porcentagem do PIB, tem como fim prevenir esse estigma. Todavia, em Catingueira, para as crianças, essa estigmatização não ocorre. Segundo elas, o recebimento do PBF está condicionado à frequência escolar e não à renda da família. Para elas, não importa se a família é rica ou pobre, desde que tenha crianças na escola, o recebimento do benefício deveria ser garantido. De forma que, para as crianças, o Programa não estigmatiza o pobre. Veja o extrato do grupo focal em que falam Lucas e Nildo, ambos com II anos:

Pesquisadora Patrícia: E tem alguém rico aqui em Catingueira que recebe o Bolsa Família? 
Lucas: Tem.

Pesquisadora Patrícia: Tem?

Lucas: Eu acho que tem.

Pesquisadora Patrícia: Porque tu acha que tem?

Lucas: Eu acho que tem. Porque as que filhas dele estudam, aí tem que receber também.

Nildo: Agora não receba?

Se é a frequência escolar que garante o benefício, logo, entende-se que as famílias sem criança em idade escolar não deveriam receber. Nathanaelly (Io anos) escreve:

\section{[...] Para as mães poderem receber o Bolsa Familia \\ todas as mães devem ter crianças, se não tiverem crianças não podem receber.}

Isso leva-nos a curiosa constatação de que a punição prevista no Programa incide apenas sobre as famílias com crianças em idade escolar. Em outras palavras, as famílias sem crianças em idade escolar não estão sujeitas à suspensão ou corte do benefício, uma vez que não se submetem à condicionalidade escolar. Esta consideração atiça o debate em torno da legitimidade do caráter punitivo do direito à escola, agora de um outro ponto de vista - já que a punição é prerrogativa apenas de um tipo de família. Aqui temos uma oportunidade para pensar a legitimidade das condicionalidades e o debate em torno dos direitos humanos e de cidadania que elas suscitam. (DINIZ, 2007; SILVA, 2007; ZIMMERMAM, 2006) As condicionalidades são, de fato, sujeitas a controversas, afinal, o

\footnotetext{
6 Referindo-se ao dono do maior estabelecimento comercial da cidade.

7 Interjeição que, aproximadamente, quer dizer: "Como não receberia?"
} 
acesso à escola é um direito. Além disso, concordo com Hanlon e colaboradores (20IO) quando afirmam que os pobres querem ver seus filhos escolarizados, mas lhes faltam dinheiro para garantir esse sonho: transporte escolar, uniforme, calçados, material escolar resultam em despesas. Os autores afirmam que não há nenhuma evidência de que as condicionalidades de fato funcionem. (HANLON; BARRIENTOS; HULME, 20IO) Segundo eles, é acesso ao dinheiro que permite que as famílias enviem seus filhos para a escola, tornando a condicionalidade desnecessária. Todavia, sendo uma condicionalidade que incide apenas em um tipo de família, aquelas com crianças em idade escolar, o debate em torno desse aspecto do programa merece um esforço de pesquisa ainda mais detalhado.

\section{Conclusões}

Nesse artigo realizamos uma breve apresentação de alguns dos resultados de pesquisas sobre o $\mathrm{PBF}$ focando o ponto de vista das crianças, embora a presença dos adultos se fizesse evidente, e enfatizando como a frequência escolar engendra moralidades dentro das famílias.

Sabendo que o recebimento do PBF é direito das crianças e sabedora de que são elas quem "trabalham", ou seja, estudam pela manutenção do benefício, as crianças estão em condições de negociar, principalmente com a mãe, detentora do direito ao recebimento do benefício, suas necessidades e seus pequenos luxos, sob a ameaça de não ir à escola. Nesses casos em que a criança não queira ir ao colégio ocorre uma negociação entre mãe e filho(a). Os termos da negociação podem ser dinheiro, um pedaço maior de carne, a liberação das atividades domésticas a que a criança é responsável, a escolha do prato a ser preparado, um ovo no cuscuz, uma peça de vestuário, liberdade para ir à lan-bouse ou visitar amigos, dentre outros. Se esses mimos não são suficientes, a mãe, por sua vez, ressalta a necessidade da frequência escolar visando o recebimento do benefício, colocando a responsabilidade do sustento familiar e da própria criança, nas mãos do aluno. A ameaça, no sentido de "se vocên não for à escola vai faltar 
o alimento para todos, especialmente para você”, parece ser o suficiente para convencer a criança da necessidade de frequentar o colégio. Observamos, então, uma responsabilização da criança pela manutenção do benefício. Responsabilidade a qual ela tem conhecimento e abraça.

Como foi dito, mesmo não sendo claramente direcionado a elas, as crianças requerem parte do benefício da família, em um claro exercício político. (PIRES; FALCÃO; SILVA, 20I4) Os membros familiares, notadamente a mãe, reconhecem a legitimidade nesse pleito, uma vez que estudar é entendido como trabalho pesado, cansativo. Na verdade, parece-nos que é justamente porque a escola é entendida como trabalho pelos membros familiares que, por isso, está sujeito à recompensa. Dessa for$\mathrm{ma}$, a elas parecem ser reconhecidos direitos individuais à riqueza familiar porque entende-se que as crianças são essenciais para a sua produção; reverberando as ideias do economista norueguês Jens Qvrotrup (2008) quando afirma que o Estado e a sociedade devem reconhecer que estudar é a forma de participação das crianças na divisão social do trabalho nas economias nacionais das sociedades contemporâneas e, portanto, elas têm direito legítimo a gozar da riqueza da nação, por exemplo, exigindo boas escolas, adaptação das cidades às suas necessidades, que sejam ouvidas sobre políticas públicas que as afetam diretamente e naquelas que dizem respeito à sociedade de modo geral, etc. Nesse sentido, esse exercício político das crianças refere-se, no curto prazo, ao atendimento de demandas imediatas, advindas da possibilidade de aquisição de novos bens de consumo pelas famílias e pelas crianças mesmas. Entretanto, não temos condições ainda de vislumbrar a quebra no círculo vicioso da pobreza em função de um reposicionamento do lugar da escola para as crianças e os adultos. Embora seja verdadeiro que as crianças estão na escola - o que as estatísticas mostram -, isso não garante que elas estejam sendo educadas ou que conseguirão realmente quebrar o círculo vicioso da pobreza. $\mathrm{Na}$ verdade, tememos pelo estado precário das escolas e da educação públicas.

Muitos são os campos de investigação abertos pelas pesquisas sobre o $\mathrm{PBF}$. Esperamos ter mostrado com esse texto a importância de incluir as 
crianças nas nossas pesquisas, como sujeitos e interlocutores legítimos. $\mathrm{O}$ conhecimento que as crianças têm do PBF é acurado e crítico. Se elas são afetadas pelas políticas sociais, nada mais coerente que ouvi-las.

\section{Referências}

ARIÈS, P. História social da criança e da familia. Trad. Dora Flaksman. 2. ed. Rio de Janeiro: Livros Técnicos e Científicos, I98I.

BENJAMIN, T. Brebotos e burugangas: analisando o "empoderamento" infanto-juvenil no Sertão Paraibano. CAOS UFPB, João Pessoa, v. I, n. I5, p. 3I-36, mar. 2010.

DINIZ, S. Critérios de justiça e programas de renda mínima. Revista Katálysis, Florianópolis, v. IO, n. I, p. IO5-II4, 2007.

FAVRET-SAADA, J. "Ser afetado". Cadernos de Campo, São Paulo, Ano I4, n. 13, p. 155-163, 2005.

FEITOSA, P. H. F. "O pobre codificado No Programa Bolsa Família e no Cadúnico”. O Cidadão Codificado: a digitalização da cidadania em bancos de dados de interesse público. 20IO. 247 f. Dissertação (Mestrado Engenharia de Sistemas e Computação) - COPPE, Universidade Federal do Rio de Janeiro, Rio de Janeiro, 2010.

GEERTZ, C. Do ponto de vista dos nativos: a natureza do entendimento antropológico. $O$ saber local. Novos ensaios em antropologia interpretativa. Petrópolis, RJ: Editora Vozes, 2002. p. 85-I07.

HANLON, J.; BARRIENTOS, A.; HULME, D. Fust give money to the poor: the Development Revolution from the Global South. Sterling: Kumanian Press, 2010.

JAMES, Allison. Giving voice to children's voice: practices and problems, pitfalls and potentials. American Antbropologist, Washington, D.C. v. Io9, n. 2, p. 26I-272, 2007. 
LAVINAS, L.; BARBOSA, M. L. de O. Combater a pobreza estimulando a freqüência escolar: o estudo de caso do Programa Bolsa-Escola do Recife. Dados, Rio de Janeiro, v. 43, n. 3, p. 447-477, 2000.

MAUSS, Marcel. "Ensaio sobre a dádiva - Forma e razão da troca nas sociedades arcaicas”. Sociologia e Antropologia. São Paulo: EPU, 1974. v. 2. MEDEIROS, Marcelo; BRITTO, Tatiana and SOARES, Fábio. Transferência de renda no Brasil. Novos estudos - CEBRAP, Campinas, n.79, p. 5-2I, 2007.

MONNERAT, G. L. et al. Do direito incondicional à condicionalidade do direito: as contrapartidas do programa Bolsa Família. Ciência \& Saúde Coletiva, Rio de Janeiro, v. I2, n. 6, p. I453-I462, 2007.

NOGUEIRA, S. G.; PIRES, F. F. “Corram riscos!” - Entrevista com o Professor Otávio Velho. Revista Antbropológicas, Recife, v. 2I, p. 329-34I, 2010. PIRES, F. F. Child as family sponsor: An unforeseen effect of Programa Bolsa Familia in northeastern Brazil. Childhood, Copenhagen, v. 2I, p. I34-I47, 2014. PIRES, F. F. ; SANTOS, P. O. S. dos ; SILVA, K. J. Elas decidem? Analisando o papel familiar da mulher a partir do Programa Bolsa Família. CAOS. Revista Eletrônica de Ciências Sociais, João Pessoa, v. 17, p. I08-I19, 20 II.

PIRES, F. F. Comida de Criança e o Programa Bolsa Família: moralidade materna e consumo alimentar no semi-árido. Política \& Trabalbo, João Pessoa, v. 38, p. 123-135, 2013.

PIRES, F. F. ; FALCÃO, C. R. ; SILVA, A. L. da. O Bolsa Família é direito das crianças: Agência Política Infantil no semi-árido Nordestino. Teoria \& Sociedade, Belo Horizonte, v. 22, p. I4I-I67, 20I4. Disponível em: <http://www.fafich. ufmg.br/revistasociedade/index.php/rts/article/view/I42/ro7>.

PIRES, F. F.; JARDIM, G. A. da S. Geração Bolsa Família: educação, trabalho infantil e consumo na casa sertaneja (Catingueira/PB). Revista Brasileira de Ciências Sociais, São Paulo, v. 29, p. 99-II2, jun. 2014.

PIRES, F. F.; NOGUEIRA, S. G. Sociologia e Antropologia - Entrevista com Professor Otavio Velho. Política \& Trabalbo, João Pessoa, v. 34, p. 23I-235, 201 I. QVORTRUP, Jens. Childhood in the Welfare State. In: JAMES, A.; JAMES, A. European Cbidbood. Cultures, Politics and Cbildhoods in Europe. London: Palgrave Macmillan, 2008. 
REGO, W. G. D. L. Aspectos teóricos das políticas de cidadania: uma aproximação ao Bolsa Familia. BIB. Revista Brasileira de Informação Bibliográfica em Ciências Sociais, São Paulo, v. 73, p. I47-I85, 2008.

SANTOS, P. O. S. dos. A invenção da infância: o programa bolsa família e as crianças da comunidade de Feira Nova (Orobó PE) no agreste pernambucano. 20I4. Dissertação (Mestrado em Antropologia) - Universidade Federal da Paraíba, João Pessoa, 2014.

SANTOS, Patrícia Oliveira Santana dos. Deixa eu falar! Uma análise antropológica do Programa Bolsa Família a partir das crianças beneficiadas do alto sertão paraibano. Trabalho de Conclusão do Curso (Graduação em Ciências Sociais), Universidade Federal da Paraíba, João Pessoa, 20 II.

SARMENTO, Manuel. "Sociologia da Infância: Correntes e Confluências”. In. Estudos da Infância. Educação e Práticas Sociais. Petrópolis, RJ: Ed. Vozes, 2008.

SILVA JARDIM, G. A. da. A casa sertaneja entre geraç̃es: os impactos do Programa Bolsa Família na cidade de Catingueira - PB. 20ıo. Trabalho de Conclusão do Curso (Graduação em Ciências Sociais) - Universidade Federal da Paraíba, João Pessoa, 2oı̀ob.

SILVA JARDIM, G. A. da. Reflexões antropológicas a partir de uma política pública para crianças. CAOS - Revista Eletrônica de Ciências Sociais, João Pessoa, n. 15, p-. 37- 45, mar. $2010 a$.

SILVA, A. L. O direito da infância num universo adultocentrado: possíveis conflitos de interesses na interpretação do ECA por crianças e adultos. In: CONGRESSO LUSO AFRO BRASILEIRO DE CIÊNCIAS SOCIAIS: DIVERSIDADE E DESIGUALDADES, 9., 20II, Salvador. Anais... Salvador: Uiversidade Federal da Bahia, 20II.

SILVA, A. L. ; PIRES, F. F. Direitos da Infância: crianças e adultos entendem a mesma coisa?. In: CONGRESSO INTERNACIONAL DA ASSOCIAÇÃO LATINO-AMERICANA DE SOCIOLOGIA, 28. 20II, Recife. Anais...

Recife: Universidade Federal de Pernambuco, 20 II.

SILVA, J. K. R. da. “Eu Compro Tudo De Pelota!”: O Programa Bolsa Família e a expansão do consumo infantil em Catingueira/ PB. Trabalho de Conclusão do Curso (Graduação em Ciências Sociais) - Universidade Federal da Paraíba, João Pessoa, 20II. 
SILVA, M. O. da S. e. O Bolsa Família: problematizando questões centrais na política de transferência de renda no Brasil. Ciência \& Saúde Coletiva, Rio de Janeiro, v. I2, n. 6, p. 1429 - I439, 2007.

SOARES, F. et al. Programas de Transferência de Renda no Brasil: impactos sobre a desigualdade e a pobreza.Centro Internacional de Pobreza (IPEA/PNUD). 2006. Disponível em: <http://www.anpec.org.br/encontro2oo6/artigos/ Ao6Ai56.pdf>. Acesso em: 7 nov. 2016.

SOUZA, E. do N. As crianças e o Programa Bolsa Familia em Catingueira (PB): uma reflexão antropológica da condicionalidade escolar a partir do ponto de vista das crianças. 20II. Trabalho de Conclusão do Curso (Graduação em Ciências Sociais) - Universidade Federal da Paraíba, João Pessoa, 20 II.

SUÁREZ et al. O Programa Bolsa Família e o enfrentamento das desigualdades de gênero - o desafio de promover o reordenamento do espaço doméstico e o acesso das mulheres ao espaço público. Relatório Compreensivo de Pesquisa. Apresentado ao Ministério do Desenvolvimento Social e Combate à Fome (MDS) e ao Department For International Development (DFID) Por agende ações em gênero cidadania e desenvolvimento, 2006. Não publicado.

SUPLICY, E. M. O direito de participar da riqueza da nação: do Programa Bolsa Família à Renda Básica de Cidadania. Ciência \& Saúde Coletiva, Rio de Janeiro, v. I2, n. 6, p. 1623-1628. nov./dez., 2007

TOREN, Christina. Mind, materiality and history: explorations in Fijian ethnography. London: Routledge, I999.

ZIMMERMANN, C. R. Os programas sociais sob a ótica dos direitos humanos: o caso do Bolsa Família do governo Lula no Brasil. Sur, Rev. int. direitos buman, São Paulo, v. 3, n. 4, p. I44-159, 2006. 